\title{
TEN REASONS FOR CONCEIVING AND CLASSIFYING POSTTRAUMATIC STRESS DISORDER AS A DISSOCIATIVE DISORDER
}

\author{
Ellert R.S. Nijenhuis
}

\section{Introduction}

In the DSM-5 (APA 2013), posttraumatic stress disorder (PTSD) has become classified in the new chapter on trauma- and stressor-related disorders. The reclassification is an improvement over PTSD's previous classification as an anxiety disorder given involvement of other intense trauma-related affects such as anger (Kardiner 1941), disgust (Badour et al. 2012), survivor guilt (Koranyi 1969), other types of guilt, and shame (Wilson et al. 2006).

The dissociative disorders that DSM-5 recognizes are placed next to, but are not a part of the trauma- and stressor-related disorders. This organization reflects "the close relationship between these diagnostic categories. Both acute stress disorder and posttraumatic stress disorder contain dissociative symptoms, such as amnesia, flashbacks, numbing, and depersonalization/ derealization" (p. 291). Another link is that particularly but not exclusively patients with complex dissociative disorders have, like patients with acute stress disorder (ASD) and PTSD, lived adverse events.

From its introduction, there have been recurrent discussions if PTSD is best seen as an anxiety disorder or as a dissociative disorder (Brett 1996; Van der Hart et al. 2005, 2006). The deliberation was far from new. Charcot (1889) and Page (1891) asserted that railway spine/ traumatic neurosis and traumatic hysteria (i.e., dissociative disorders) involved the same symptoms, hence constitute one disorder. Myers (1940) described that shell shock, a forerunner of PTSD, involves a dissociation of the personality that Janet (1907) had defined as a core feature of hysteria. Myers invented the term shell shock, because he felt that brave soldiers who broke down could not have hysteria, a disorder he and many others associated with women despite recurrent documentation that both genders can develop hysteria (e.g., Sydenham [Dewhurst 1966], Charcot 1889; Janet 1907). Still, Horowitz (1976) was clear that the disorder that was to be called PTSD involves a division of the personality. Studying Vietnam veterans, others agreed (Wang et al. 1996).

Are trauma- and stress-related disorders and dissociative disorders two of a kind? An inquiry into the matter requires crystal-clear (definitions of the) concepts of dissociation, dissociative symptoms, and dissociative disorders. This clarity does not exist in the DSM-5 and the field more generally. The terms 'dissociation', 'dissociative symptoms', and 'dissociative disorders' are defined and used in confusing and contradictory ways (Nijenhuis and Van der Hart 2010). 
For example, DSM-5 includes two subtypes of PTSD with dissociative symptoms, one for individuals older than six years, and one for younger children. Both are characterized by persistent or recurrent negative symptoms of depersonalization/derealization. However, DSM-5 also recognizes positive dissociative symptoms that occur in any form of PTSD.

The objectives of this article are to (1) explain that 'events' do not exist in isolation from individuals who experience and conceive them, (2) detail that 'traumatic events' cannot be seen as efficient causes of trauma as a biopsychosocial injury, (3) emphasize that 'trauma' cannot be fully understood in terms of material and efficient causation, but requires an analysis of its formal and final causes, (4) demonstrate that its formal cause is a dissociation of the personality as a whole biopsychosocial system, and its final cause a differentiated will, (5) provide empirical evidence that PTSD and dissociative disorders involve positive and negative, and cognitiveemotional and sensorimotor dissociative symptoms, (6) discuss that PTSD and complex dissociative disorders involve highly similar volumetric brain abnormalities, (7) functional physiological abnormalities, and (8) functional brain abnormalities, (9) discuss that PTSD and dissociative disorders essentially involve the same treatment aims and methods, and (10) conclude that the most parsimonious option is to propose and further explore a dimension of complexity of trauma-related dissociation of the personality.

\section{Trauma}

\subsection{Trauma: ontological considerations and the problem of efficient causation}

What is trauma and what causes it? The common understanding is that trauma constitutes an isolated event or constellation of events:

trauma as event(s) $\rightarrow$ causes $\rightarrow$ physical or mental disruption

For example, the DSM-5 A criterion for PTSD (and ASD) regards and delimits the concept of trauma to actual or threatened death, serious injury, or sexual violence. The concept of trauma as an isolated event is empirically overinclusive, because a particular adverse event does not injure all who live or observe it. The concept is empirically underinclusive, because individuals can develop biopsychosocial pathology after other events such as emotional neglect and maltreatment (Draijer and Langeland 1999; Tomoda et al. 2010). These empirical grounds preclude the definition of 'trauma' as an isolated event.

A conceptual problem is that the term 'trauma' means 'injury'. To avoid confusion, it is better to reserve the term 'trauma' for a particular injury, and to exchange the term 'trauma as an event' for the term 'adverse event' or 'potentially traumatizing event'.

While this move constitutes a conceptual and empirical improvement, it does not remedy another nasty problem that concerns the presumed causal relationship between an isolated adverse event and the injury that may follow. In a mechanistic worldview, injuries are caused by adverse events: 
isolated adverse event $\rightarrow$ mechanically causes $\rightarrow$ trauma as injury.

Physically it might be a blow to the head. Mentally it could be a metaphorical blow to the mind such as betrayal. Philosophical realists concede that adverse isolated events might, as any event, constitute a collection of stimuli existing in the objectively existing world to which an organism reacts. They hold that "the world is objectively real, you are part of this objectivity, and scientists can study and grasp the world in an objective fashion because there is universal reason and because they have access to this universal reason":

isolated adverse event as a part of objective reality $\rightarrow$ affects $\rightarrow$ subject as a part of that reality.

With Aristotle, who distinguished between four different types of causes, one might say that particular isolated adverse events can be the efficient cause of the injury, that is, to events that bring the injury into being:

isolated adverse events as efficient cause $\rightarrow$ can linearly cause $\rightarrow$ trauma as injury.

The deep problem is that an event would not be if it were isolated from an experiencing and knowing subject. Without a conscious subject, an event (an object, a constellation and dynamic of objects) would not exist, the philosophical idealist explains. Schopenhauer (1818/1844/1958) agreed that the world is our idea, but he added that without matter--without an embrained body and an embodied brain--there would be no subject. Without a mind, there is no matter, and without matter, no mind could exist. Brain, body, and environment occur together, constitute each other, and are dependent on each other (Northoff 2003; Schopenhauer 1818/1844/1958):

$$
\begin{aligned}
& \text { subject } \leftarrow \text { co-occurrence } \rightarrow \text { object } \\
& \text { subject } \leftarrow \text { co-constitution } \rightarrow \text { object } \\
& \text { subject } \leftarrow \text { co-dependency } \rightarrow \text { object }
\end{aligned}
$$

Ontologically, there are intrinsic relationships between the brain, body, and the environment. The living brain cannot exist without a wider living body, just as this body requires a living brain. And the embodied and embrained subject necessarily exists in an environment, whereas the environment would not exist, if there were no conscious subject. There is, thus, ontological embedment of the brain, body, and environment:

$$
\begin{aligned}
& \text { brain } \leftarrow \text { intrinsically related } \rightarrow \text { body } \\
& \text { brain/body } \leftarrow \text { intrinsically related } \rightarrow \text { material/social environment }
\end{aligned}
$$

The realization that brain, body, and environment exist and change in virtue of each other moves philosophy and psychology from absolutism to relativism, from thinking of subject and object as isolated entities with their own 'absolute' ontological properties to an understanding of subjects and objects in terms of ontological relationships. There is no environment and there 
are no events as changes in the environment as the respective context that exist in separation of a subject. What exist are dynamic configurations of brain, body, and environment (Northoff 2003).

With respect to trauma, there is ontological embedment of conscious subjects (brain, body) and adverse events. These embedded adverse events involve changes in the actual and historical environment as their context that a subject can observe (i.e., sense, perceive, conceive) and effectuate (Northoff 2003). Embedded events are adverse when these changes are adverse to the involved subject. Embedded events that may cause a biopsychosocial injury are adverse/ potentially traumatizing. Those that have caused this injury, have been traumatizing.

To say that an embedded event was traumatizing means that it was an important dynamic causal factor with respect to the biopsychosocial (see below) injury that ensued. The event is not the only causal factor. For example, the probability of an injury will also depend on contextual embedded events such as previous adverse embedded events, lack of social support in the aftermath of the event(s), the subject's age and stage of brain maturation, and genetic make-up.

To resume, the comprehension of events as isolated events must be rejected. Any conceptualization of 'trauma's', or 'traumatic' or 'traumatizing events' as isolated efficient causes of a disorder is inconsistent with the existence of intrinsic ontological relationships between subject and object. There is no exclusive room for isolated efficient causes in embedment. Embedment predominantly implies dynamic causation, that is, ongoing mutual determination and reciprocal causal relationships between brain, body, and environment.

The assumption of isolated events is characteristic of realism (i.e., the idea that there exists a subject-independent real world) and empiricism (i.e., the idea that one can objectively observe this objectively existing world). The assumption of the existence of a mind in isolation of a brain, body, and environment characterizes (solipsistic/subjective) idealism (i.e., the idea that the world is a mere subjective idea). The notion of intrinsic relationships between brain, body and environment that manifest in dynamic configurations is incompatible with these philosophies and sciences built on them. Hence, ontological embedment calls for a science that realizes the principles of ontological relativity, of dynamic configurations of brain, body, and environment, and of embedded events as observable and to be effectuated changes within the environment as their context (e.g., Northoff 2003; Varela 1996).

\subsection{Trauma: epistemic considerations}

Epistemically, we do not sense, perceive, conceive, and react to isolated stimuli or to a collection of isolated stimuli. We rather experience and know events as organized whole structures, and only as changes in the environment as the respective context: "What happens, happens in a world, and that world is never the same; panta rhei". Within limits we can distinguish different elements of an event, but experience and know them as elements of an event in which they are embedded. We also experience and know events as changes in the environment that exist in the context of other past, present, and anticipated events: "What happens now relates to what was and will be". We embed events spatiotemporally. Given dynamic configurations of brain, body, and environment, they include ourselves as experiencing and knowing subjects.

We thus experience and know adverse events as environmentally and historically embedded: 


\section{Ellert R.S. Nijenhuis}

The meaning of the adverse event for the individual who lives it is necessarily co-dependent on the context of the current environment, as well as on the embedded events that preceded and are anticipated to follow the current one. An understanding of trauma thus must include an understanding of the spatiotemporal context in which this injury involved. PTSD's A criterion is problematic, because it lists some isolated, 'objectively existing' events, and does not consider that events are subject-dependent and spatiotemporally embedded.

Individuals need not be conscious of this embedment and its implied relativity. Large parts of the mind remain unconscious or operate preconsciously, precluding a direct route to understanding. However, there are indirect ways to access unconscious or preconscious mental states. For example, scientists can use subliminal exposure to trauma-related cues to explore preconscious reactions to these signals (see below for an example with regard to trauma).

A deep and general scientific problem is that scientists cannot tell by observing the body/brain what its owner sense, perceived, conceived, et cetera, including what experiencing and knowing a particular subliminal or supraliminal event is or was like. Consciousness is irreducible to something else (Varela 1996). For example, in most cases, events do not have a given, precoded meaning for us; in this sense, there is no 'information' to 'process'. We rather unconsciously, preconsciously, or consciously assign meaning to observed environmental changes. True, there are a number of 'unconditioned stimuli'--that is, stimuli as elements of embedded events--that have gained a prefixed meaning in evolution. 'Meaning' stands in this case for a particular evaluation (pleasurable, aversive, or dangerous) and typical associated 'unconditioned' reaction (approach, avoidance). However, in most cases, we must assign meaning to observed changes in the environment as we evolve:

\section{subject $\rightarrow$ experiences, knows, assigns meaning to $\rightarrow$ embedded events}

Embedded adverse events can therefore not be seen as changes within the environment as the respective context that have a preset meaning. These events probably include 'unconditioned stimuli', but these are elements of embedded events, and individuals evaluate embedded events, not isolated stimuli. For example, intense pain in the context of sexual abuse by a caretaker is bound to be different from intense pain in the context of sexual abuse by a stranger and subsequent recognition and emotional support from a loving and trusted caretaker. And sexual abuse in childhood is different from sexual abuse in adulthood if the involved adult has had a safe previous childhood and has gained high integrative capacity, in part because the brain has soundly matured.

In sum, the A criterion for PTSD and ASD must be rejected. The concept of embedded events implies that it neither makes sense to use the term 'event' in the sense of an isolated event, nor to constrain the types of embedded events that are adverse and potentially traumatizing a priori. The risk that a particular embedded event will be injurious can be statistically predicted, but whether it was adverse or traumatizing for an individual who lived it can only be assessed de post facto.

\subsubsection{Epistemic pluralism}

How are embedded events experienced and known? There is epistemic pluralism (Northoff 2003) since embedded events can be known from different person perspectives. The first-person 
perspective (FPP) concerns subjective, phenomenal experience, centered in the experiencing subject's body. FPP entails what it is like to be an 'I', to be a subject, to have experiences, to be an agent, and to have a personal point of view. For example, FPP concerns what it is like to see redness, to enjoy music, to be curious, scared, horrified, in pain, or disgusted.

The quasi-second person perspectivel (QSPP) pertains to the phenomenal relationship between an experiencing first-person, and this person's phenomenal judgment regarding himself or herself, resulting in 'I-me, myself, mine' relationships. It addresses agency ("I act to achieve my goal") and ownership ("I and my action, hand, thought, goal"). For example, QSPP involves the personification involved in the phenomenal judgment that "I feel my hand", or "I am angry at myself".

The second-person perspective (SPP) comprises 'I-You' relationships. It denotes the phenomenal relationship between 'I' and 'You,' and involves a phenomenal judgment grounded in FPP and QSPP. For example, one might phenomenally experience and judge that "I am glad to meet you, and you seem to be happy to meet me as well. Though we share the same mood, we are also different". In chronic traumatization, a child may phenomenally experience and judge, "I need you, but you scare me", or "You say I am bad. You must be right, because you're my mother, and because you punish [i.e., abuse] me".

The child's mother, however, may not perceive the child as a subject when she is abusive. Guided by their needs, perpetrators relate to the children they abuse, maltreat, and/or neglect as 'things'. This perspective would reflect an 'I-object' relationship. 'I-object' relationships involve a third-person perspective (TPP) if the judgment with respect to the content of one's perception or conception is not phenomenal but physical. In this epistemic relationship, there is an 'I' who physically judges an object.

\subsubsection{Epistemic dependency}

Whereas TPP is grounded in FPP, QSPP, and SPP, this fact is often ignored. Taking the 'I' out of the 'I-object' relationship creates the illusion that TPP provides direct access to a part of an objectively existing world, to a world that exists in isolation of experiencing and knowing subjects. For example, the idea that science is 'objective' constitutes a misapprehension. The scientific TPP is phenomenally and epistemologically dependent on the other person perspectives. Science is a human (ad)venture. We are not like the Baron of Münchhausen who managed to lift himself and his horse out of a swamp by holding on to the tail of his wig.

\subsubsection{PTSD and DSM-5 dissociative disorders}

As detailed more in the next section, these disorders include and are united by profoundly shifting dynamic configurations of brain, body, and environment, and the implied epistemic perspectives. Due to embedded adverse events, these are insufficiently integrated in the

Northoff (2003) refers to 'I-me, myself, mine' relationships as the second-person perspective (SPP). However, he also uses the term SPP to denote 'I-You' relationships. To avoid confusion, I use the term QSPP for 'I-me, myself, mine' phenomenal relationships and reserve the term SPP for 'I-You' phenomenal relationships. 


\section{Ellert R.S. Nijenhuis}

individual's personality. An understanding and repair of this organization of the individual's personality requires an understanding of the intrinsic relationships between brain, body, and environment, hence must consider the organism-environment system as the basic unit of analysis (Järvilehto 1998).

\section{The formal cause of trauma}

Apart from efficient and material causes, Artistotle proposed the concepts of formal cause and final cause (Northoff 2003). Formal cause describes what makes a 'thing' the sort of 'thing' it is, rather than another 'thing'. Formal causation pertains to organization. For example, bricks, mortar, and wood must be organized in a particular fashion to constitute a house. Final causation characterizes the goal toward which something aims. The final cause of a house is a place to live; without that understanding, it would be a mystery what particular material constructions are about. Human experience and behavior are incomprehensible if it remains unknown what an individual is trying to achieve. Whereas isolated material cause (matter $\rightarrow$ causes changes in $\rightarrow$ matter) and efficient cause (one isolated thing $\rightarrow$ causes changes in $\rightarrow$ another isolated thing) are incompatible with 'embrainment'/embodiment/embedment, formal and final causation apply.

\subsection{Dissociation of the personality}

The formal cause of trauma is the existence of two or more conscious subsystems of the personality as a whole biopsychosocial system (Nijenhuis et al. 2002; Van der Hart et al. 2006). This statement can be clarified as follows.

\subsubsection{Integrative actions}

Integration includes several actions: synthesis, personification, and presentification (Van der Hart et al. 2006). Synthesis stands for creating cohesion and coherence among current sensorimotor, emotional, cognitive, and behavioral actions (Janet 1907). For example, an abused child must synthesize pain, fear, freeze reactions, and thoughts like "this is horrible". Personification entails linkage of these syntheses so that one becomes their agent ("I freeze") and owner ("The experience happens to me"). Presentification is the action of connecting one's personified syntheses to each other to form a life history (Janet 1928). The connection must be such that the actual present is experienced and known as the most real. The near past and anticipated future should also be quite real for the individual, and generally more real than the distant past and anticipated future. Presentification of the past commonly implies putting experiences in symbols. Normal autobiographical memories are thus mostly stories told, that is, narratives. Realization is more than experiencing and knowing that an event or fact is real. It includes acting responsibly on the basis of the experienced and conceived reality.

Trauma involves major problems of integration. For example, bodily and emotional anesthesia reflects incomplete synthesis. Depersonalization symptoms involve a lack of personification, and sensorimotor and emotional reenactment of traumatic memories constitutes a lack of 
presentification. These symptoms relate to a lack of integration of the personality in trauma when that which traumatized individuals do not synthesize, personify, presentify, and realize is not gone from them (see 2.1.3.).

\subsubsection{Autobiographical memory}

Individuals commonly synthesize, personify and presentify embedded events that are of significance to them in the context of their personality. Embedded in their life history, these events are available for their explicit, narrative, hence explicit symbolic recollection and implicit memory (e.g., skills individuals have gained).

Action necessarily includes a particular vehicle (e.g., to feel, to perceive, to remember) and content (e.g., a feeling, a perception, a memory). As contents, experiences and autobiographical memories do not involve representations of an outer world. Given dynamic configurations of brain, body, and environment, there is no objective external world, no Kantian 'thing in itself' that could get internally represented. Engaged in the actions of experiencing and knowing the world, individuals rather generate presentations or conceptions. To phenomenally experience is to have phenomenal experience (FPP). To phenomenally judge is to have phenomenal judgments (QSPP, SPP). To physically judge is to have physical judgments (TPP).

In the case of autobiographical memory, the action is not to retrieve encoded and stored representations from the mind's internal library. Autobiographical memory is not an inner library filled with books than contain traces (representations) of things past. (For major problems of representationalism see, Braude 1995; Northoff 2003.) We do not represent current or past outer isolated events, but enact or reenact embedded events.

As a vehicle, recalling the past is telling a personal story (Janet 1928). The storytelling involves a symbolic and personified reenactment of embedded events, and the story entails phenomenal experiences and judgments in the form of presentations or conceptions. Whereas these may be lively, they are not re-lived, so that the past and present are not confused. Recollecting individuals know they relate past personal experiences. They live the story, not the original experience, they remain oriented in place, time, and identity. The involved presentation/conception remains a simulation of past experiences and judgments when individuals have synthesized, personified and presentified the past.

\subsubsection{Traumatic memories}

Symbolizing and integrating exceptionally adverse embedded events are most difficult actions. They may be too difficult to achieve. The difficulty includes the problem of realization: fully experiencing and knowing that something is the case, and acting on the implications of that reality (Van der Hart et al. 2006). The difficulty of realization is relative to individuals' integrative capacity and the nature of the adverse embedded event and its context. Integrative capacity is not a given, stable feature, but is dependent on a host of features such as the degree of brain maturation, affect regulation skills, social support, prior embedded events, and the event's nature. For example, abuse by a caretaker is generally more difficult to integrate than abuse by a stranger, and secretive interpersonal abuse is generally harder to integrate and realize than 
socially shared and public natural disasters (Liotti 2006; Van der Hart et al. 2006).

Individuals who reenact a traumatic memory do not realize that they, as one would physically judge in TPP, are engaged in a simulation. They experience that the traumatizing event happens "here" and "now", and their phenomenal experience and conception of who they are is not "the one I was at the time" but rather "the one I am, right here, right now." While reenacting, they may feel fear, anger, shame, pain and disgust in FPP. In this context, they commonly relate to themselves in QSPP (e.g., "my body is endangered, I must defend myself") and others in SPP (e.g., "my mother hates and hurts me"). Their physical judgment pertains to observed objects. For example, in the context of sexual abuse by a man, they may physically judge that "the smell of [the perpetrator's] after shave is disgusting". When reenacting, traumatized individuals may phenomenally judge that an actually safe individual such as the partner or the therapist is a potential threat or even the actual perpetrator. Their physical judgment may be that the therapist's door is locked to block their escape route.

The reenacting 'identity' (the 'I' or phenomenal self of the past) does not include the posttraumatic 'identity' (the present phenomenal conception of self). If the individual's present phenomenal conception of self were available to the individual's reenacting phenomenal conception of self, the latter would experience and know that he or she is living an actual safe 'here' and 'now', and reenacting a former traumatic experience. Bystanders such as the therapist may physically judge that the patient is reenacting a terrible past. They can combine this TPP physical judgment with a SPP phenomenal judgment that the reenactment entails an awful experience for the patient. This sympathetic judgment is grounded in their FPP imaginationbased experience and QSPP imagination-based phenomenal judgment that experiencing what happened the patient by oneself would be horrific.

\subsubsection{Emotional and apparently normal parts of the personality}

When individuals do not succeed in integrating an adverse embedded event, they will evolve different dissociative subsystems of the personality as a whole embedded biopsychosocial system (Nijenhuis and Van der Hart 2011; Nijenhuis and Den Boer 2009; Nijenhuis et al. 2002; Van der Hart et al. 2006). In trauma, there are at least two different prototypical dynamic subsystems or dissociative 'parts'. Each includes a more or less extensive set of unconscious, preconscious, and conscious dynamic states. Some of these dynamic states are specific for a dissociative part, whereas others may be shared.

Dynamic states concern particular organizations of physical states (i.e., neuronal, physiological states) and mental states. Both kinds of states are oriented to the same embedded events and the subjects' implied goals (Northoff 2003). Ontologically, dynamic states involve different dynamic configurations of brain, body, and environment. Epistemically, Northoff (2003) refers to these different organizations as the First-Brain Perspective and the First-Person Perspective. Pertaining to the same embedded event, the biological and psychological perspectives can be indirectly linked. This formulation avoids philosophical dualism of matter and mind. A direct link between consciousness and matter is not possible since consciousness is irreducible to anything else. However, indirect links are within reach (Northoff 2003; Varela 1996). I concede that these links also apply to the other epistemic brain and person perspectives (e.g., the Second-Brain 
Perspective and the Second-Person Perspective). The implication is that dissociative subsystems of the traumatized individual's personality can be conceptualized and studied as biopsychosocial subsystems. The challenge is to carefully assess, describe, and link these different perspectives.

There is at least one dissociative dynamic subsystem or 'part' that is fixed in a 'traumaworld', that is, in reenacting this world from time to time, and in a particular way (see below). This prototypical conscious subsystem of the personality is metaphorically addressed as 'emotional part' (EP). There is in addition at least one other conscious subsystem that is oriented to functioning in present daily life. As this part, traumatized individuals attempt to act as if nothing is wrong, among others by evading EP. This prototypical subsystem is metaphorically addressed as 'apparently normal part' (ANP). ANPs have not (sufficiently) integrated EPs and the traumatic experience in which these parts are fixed, and do not integrate these when they are occasionally intruded by them. Dissociative parts can encompass a few (most EPs) or a larger (most ANPs, some EPs) set of dynamic states.

Most traumatized individuals alternate between these different parts that may be activated in a sequence or in parallel. Dominant parts may or may not be aware of that parallel activation, or may not understand that subdominant parts are influential. EPs and ANPs remain insufficiently integrated for the duration of the disorder.

\subsubsection{Constraint on the concept of dissociative parts}

Few individuals are fully integrated. Anyone can find it hard at times to coordinate contrary desires, such as the desire to relax and to work. In several forms of psychopathology one urge has become very strong to the expense of others. For example, patients with agoraphobia are guided by defense (fear and flight) more than by social engagement (e.g., meeting friends in a bar).

One might ask why agoraphobia would not involve a dissociation of the personality with one part who wants to go out and another part who is too scared to leave home? The major reason to reject this conceptualization is that concepts should be sensitive (i.e., they must capture crucial phenomena) as well as specific (i.e., they should only capture these phenomena). If it would be said that agoraphobia includes dissociative parts, few mental disorders would not be dissociative. The concept of dissociative parts thus needs constraints to serve specificity. The best delimiter is the requirement that dissociative subsystems of the personality involve their own FPP, QSPP, SPP and TPP, because it is this phenomenon that distinguishes patients with dissociative disorders from mental healthy individuals, patients with other mental disorders, and patients with 'ego-states'.

Dissociative parts of the personality are described as "distinct personality states" in DSM5. However, empirically they are not isolated, because they overlap and relate to each other in certain regards. For example, they may share particular memories (Huntjens et al. 2003), and may have similar subjective, physiological, and neural reaction patterns to reminders of personal events that were not threatening to them (Reinders et al. 2006). Moreover, the different personality states can intrude each other. These intrusions can be adverse, thus cause distress (e.g., voices shouting or crying).

The conceptual and empirical problem of the term 'personality state' is that anyone's personality encompasses a multitude of different states, and that 'dissociative personality states' 


\section{Ellert R.S. Nijenhuis}

commonly include many different states. Since the human personality constitutes a whole biopsychosocial system that guides enduring patterns of experience, thought, and behavior, dissociation of the personality is better conceptualized as a division among two or more conscious subsystems or parts (see 1.5). Each includes a variety of mental and brain states that relate to his or her dispositions and actions, some of which are unique.

The concept of 'distinct personality states' in DSM-5 involves an exaggeration that hinders to see or accept the fact that several other mental disorders also involve conscious subsystems or parts that are insufficiently integrated. PTSD is one of these.

\subsection{Dissociation of the personality in other mental disorders than in DSM-5 dissociative disorders}

PTSD involves nonintegrated traumatic memories that recurrently intrude the patient. Criterion B3 pertains to intruding "dissociative reactions (e.g., flashbacks) in which the individual feels or acts as if traumatic events were recurring". Criterion B1 states that the patients have "[r] ecurrent, involuntary, and intrusive distressing memories of the traumatic event(s)". Criterion B2 is that they experience "[r]ecurrent distressing dreams in which the content and/or affect of the dream are related to the traumatic event(s)".

The B1-3 forms of reenactment of traumatic memories do not concern a bundle of isolated reactions to isolated stimuli as efficient causes, but are organized actions in the context of experienced and perceived embedded events. Given this organization, they constitute a formal cause. Major questions in this regard are: What organization within the personality is it that is intruding, what organization is intruded, and what are the epistemic perspectives of these organizations? (Their final causes are explored in section 3).

The organization of traumatic memories can take different forms. One form is hyperaroused emotional and sensorimotor reenactment, and another hypoaroused reenactment with emotional and bodily anesthesia, depersonalization and derealization. These forms can co-exist, and both include disorientation in time and place. The patients lose the orientation on the 'here and now', and become emotionally and physically immersed in a phenomenal 'here and now' that actually involves a 'there and then'.

It is commonly overlooked or ignored that reenactment of a traumatic experience involves its own person perspectives. For example, Criterion B-3 mentions more or less complete loss of awareness of present surroundings. These "dissociative reactions" (APA 2013, p. 271) include their own phenomenal experiences (FPP), phenomenal judgments (QSPP and SPP), and physical judgments (TPP). Traumatic reenactments thus entail their own epistemic pluralism (see 1.2.1.) and epistemic dependency (see 1.2.2.). They entail an organized set of syntheses that are not or not sufficiently presentified. However, they are personified because there is an EP, an 'I' who relives dreadful phenomenal experiences (FPP). This EP phenomenally judges himself or herself (QSPP) and other individuals (SPP), and may physically judge objects (TPP).

When the reliving is massive, the patients become the one they were when they became injured (EP) and lose their present safe existence and associated conception of who they are (ANP). During lesser intrusions, the patients remain present as ANP, but become influenced or 
even flooded by dynamic traumatic states of EP. For example, ANPs may hear EPs' voices.

In conclusion, PTSD constitutes a dissociative disorder for the same reasons that define minor and major forms of dissociative identity disorder (DID) as dissociative disorders. Ontologically, epistemically, and empirically, all involve at least two different and dissociated sets of conscious dynamic configurations of brain, body, and environment described as dissociative parts of the personality as a whole system. ANPs' and EPs' dynamic configurations manifest as dynamic states. These dynamic states, as well as the epistemic pluralism and epistemic dependency they imply, are clinically observed and empirically testable. Empirical evidence comes in various forms and is presented below (see 4-9).

\subsubsection{PTSD with dissociative symptoms}

A recent proposal that has been accepted by the authors of DSM-5 is that there is (common) PTSD with hyperaroused reexperiencing of traumatizing events, and PTSD "with dissociative symptoms" (APA 2013; Lanius et al. 2012). In this conceptualization, "dissociative" does not stand for a lack of integration of different subsystems of the personality but for the negative symptoms of depersonalization and derealization. The common form of PTSD would not be dissociative, because patients with this condition do not respond to reminders of traumatizing events with these negative symptoms.

However, as discussed in 2.2., there are also positive dissociative symptoms such as intrusions of nonintegrated traumatic memories, voices, feelings, affects, thoughts and actions that belong to parts of traumatized individuals' personality that these parts have not (sufficiently) integrated. Lanius et al. and the authors of DSM-5 actually accept the existence of these positive dissociative symptoms. For example, they use the term 'dissociation' in the sense of a dissociation of the personality (as in DID, APA, p. 291). They also recognize "positive dissociative symptoms" (APA, p. 291) and "dissociative reactions (e.g., flashbacks) in which the individual feels or acts as if traumatic events were recurring" (APA, criterion B3, p. 271). Since these authors' use of the terms 'dissociation' and 'dissociative symptoms' is contradictory (see 3.4.), the term 'PTSD with dissociative symptoms' must be rejected.

\section{Trauma: final causes of dissociative subsystems}

To understand human experience and behavior is to understand final causes. For example, patterns of physiological and brain activity do not tell scientists what their subject of investigation was feeling, thinking, and trying to achieve. Brain science does not tell why a dissociative patient becomes hyperaroused or hypoaroused in reaction to reminders of traumatizing embedded events, or how matter generates mind. The social sciences require a conjoint effort of scientists and participants in studies in which the plural epistemic perspectives of the participants in the study are carefully assessed and compared with and linked to TPP measurements (Bitbol 2008; Varela 1996).

As Janet $(1901 / 1977,1907)$ formulated, dissociation of the personality (as a formal cause) involves more than subsystems of ideas, more than mental contents regarding self, others, objects, 


\section{Ellert R.S. Nijenhuis}

events, and environment as generated by different co-dependent epistemic person perspectives. Dissociative parts also exert their own functions. They have their own final causes. Each has its own sensations, perceptions, and conceptions, and each experiences and displays an urge to achieve one or a limited set of particular goals. Grasping these two characteristics is key to understanding dissociative parts, including their dynamic relationships with each other and with other individuals (e.g., therapists, perpetrators, family members, scientists).

\subsection{The different wills of different dissociative parts}

This formal and final causation implies a recurrent dissociative inconstancy of the will in trauma. A collection of sometimes hard to coordinate urges that precede and constrain thought, will is an untiring, demanding, and capricious customer. In evolution, will has become differentiated to constitute the heart of several emotional action systems (Panksepp 1998; Panksepp and Biven 2012). To prosper, mammals developed action systems for energy management, exploration, attachment, social engagement, play, and procreation that involve wills to function in daily life. Mammals also developed a complex action system for defense that includes startle, freezing, flight, defensive fight and tonic immobility. Mentally healthy individuals can by and large coordinate their different strivings such as their desires to eat, relax, sleep, attach, socialize, play, have sex, and defend, although conflicts among different wills are strange to none. Traumatized individuals do not achieve this coordination and integration, and jump from one will to the next. These jumps involve major epistemic shifts between different 'I's'. The primary will of ANPs is to function in daily life and evade EPs' and their traumatic memories. EPs' predominant urge is to defend the body and life itself in the face of actual and perceived threat.

\subsection{The inconstant will in PTSD}

In simple PTSD, there is commonly one ANP and one EP. Many EPs are mediated by defensive strategies that predominantly involve the sympathetic nervous system, hence hyperarousal (startle, freezing, flight, and fight). Other EPs are mediated by the dorsal vagal parasympathetic nervous system associated with tonic immobility, by attachment cry, or by social dominance. Hyperaroused EPs are as dissociative as hypoaroused EPs or nonaroused ANPs. Hence, Lanius et al. and DSM-5's "PTSD with dissociative symptoms" can involve an ANP or an EP engaging in tonic immobility. To know what applies, scientists and clinicians should assess patients' behaviors and pluriform epistemic perspectives. Scientists should ask, "what were you feeling, thinking, doing, what did you want to achieve, how did you perceive yourself, other individuals, objects, the goal of the experiment?” (see 8 and 9).

\subsection{The inconstant will in more complex dissociative disorders}

In more complex dissociative disorders there are typically one or more ANP, and more than one EP, some of which can become quite evolved. For example, complex PTSD commonly 
involves one ANP and more than one EP that can be of different types.

The more patients have experienced early childhood abuse and neglect, the more likely it becomes that some EPs are predominantly engaged in attachment cry, and some other EPs in social dominance. As ANP, they try to function in daily life, and to that end, act as if nothing is wrong - when they can. Fragile EP engaging in attachment cry, cry to be seen and heard. Prey lost from the heard must give alarm signals, so that the mother will notice the loss, look for her child, and take him or her back to the group. If the chronically traumatized child would only encompass ANPs and Fragile EPs, he or she would not have any sense of power. Hence, mediated by the will system of social dominance, the child develops a Controlling EP who tend to imitate perpetrators. Controlling EPs despise Fragile EPs and powerless ANPs. They may utter slander regarding these parts, mutilate them, make sure that they get neglected and abused again, spoil their few pleasures, prevent, forbid, and ruin attachment relationships, or try to kill them, believing that they themselves will survive the 'homicide'.

To take stock, there is a trinity of trauma in chronic traumatization. The formal cause is the dissociation of the personality in three major prototypical conscious parts: ANPs, Fragile EPs, and Controlling EPs. Each involves his or her own epistemic pluralism and dependency: FPP, QSPP, SPP, and TPP. These person perspectives relate to their different particular dynamic configurations of brain, body, and environment. Guided by different basic urges that precede cognition, each is differently 'embrained', embodied, and embedded. Children who are chronically neglected and abused by caretakers must live daily life with them, and are in this frame as ANPs guided by action systems for daily life. They must also attach to them as ANP, but only to some degree, because as this part, the child cannot afford to feel too much. Some Fragile EPs may also attach to them, but EPs more generally defend their body and life when attacked by the caretaker(s). As Controlling EPs, survivors imitate the perpetrator(s) to safeguard a degree of control. These parts reenact caretakers' slander and betrayal. The embedded events that survivors epistemically situated in the outer world, become mirrored in their personality. ANPs ignore EPs as much as possible. Fragile EPs feel vulnerable, fear other parts, and defend against them. Controlling EPs are controlling but may have difficulty affecting avoidant ANPs and Fragile EPs engaging in tonic immobility. Trauma, thus, is a struggle of ignorance, fragility, and control.

\subsection{The concept of dissociation}

As noted above, scientific and clinical concepts must capture all relevant phenomena (i.e., sensitivity), but only relevant phenomena (i.e., specificity). The original conceptualization of dissociation met both criteria. Dissociation and dissociative disorders originally pertained to a division of an individual's personality as a whole biopsychosocial system in two or more subsystems of ideas and functions (Janet 1907). Ideas involved sensations, perceptions, thoughts, memories, and fantasies. Functions mainly captured that which an individual wishes and tries to achieve. In recent years, the concept and definition of dissociation and dissociative disorders has become much broader in certain regards, and far narrower in other respects. Dissociation can now pertain to common and various non-pathological shifts in level and field of consciousness, 
a mental defense, a division of personality, symptoms of this division, mere symptoms, or still other phenomena. Even absorption and selective attention would be dissociative. Amid this broadening that is at odds with the criterion of specificity, some authors restrict dissociation to several negative symptoms, and often only to negative cognitive-emotional symptoms (e.g., low levels of consciousness). In this context, they regard sensorimotor dissociative symptoms/ disorders as conversion symptoms/disorders. Given positive dissociative cognitive-emotional symptoms and positive and negative sensorimotor dissociative symptoms, this narrowing of the domain of dissociation conflicts with the criterion of sensitivity.

The conceptual confusion regarding dissociation has negative implications for classification, clinical practice, and research. Without specification it is not clear what phenomenon or principle clinicians and researchers have in mind when they use the term. This specification is seldom provided: Most studies of dissociation do not include a definition of the concept. The result is confusion. For example, what does a reported correlation of 'dissociation' and some other phenomenon means when 'dissociation' is left undefined?

The following definition that involves a slight alteration of a previous version (Nijenhuis and Van der Hart 2011) is intended to clear a cloudy field:

Dissociation in trauma entails a division of an individual's personality, i.e., of the dynamic, biopsychosocial system as a whole that determines his or her characteristic mental and behavioral actions.

This division of personality constitutes a core feature of trauma. It evolves when the individual lacks the capacity to integrate adverse experiences in part or in full, can support adaptation in this context, but commonly also implies adaptive limitations.

The division involves two or more insufficiently integrated dynamic, that is changeable, but excessively rigid subsystems. These subsystems exert functions, and can encompass any number of different dynamic configurations of brain, body, and environment. These different configurations manifest as dynamic actions and implied dynamic states. The dissociative subsystems can be latent, or activated in a sequence or in parallel. Each dissociative subsystem, i.e., dissociative part of the personality includes its own, at least rudimentary person perspectives (FPP, QSPP, SPP, and TPP), that is, its own epistemic pluralism and epistemic dependency.

As each dissociative part, the individual can interact with other dissociative parts and other individuals, at least in principle. Dissociative parts maintain permeable biopsychosocial boundaries that keep them divided, but that they can in principle dissolve.

Phenomenologically, this division of the personality manifest in dissociative symptoms that can be categorized as negative or positive, and cognitive-emotional or sensorimotor.

\subsection{The theory of structural dissociation of the personality (TSDP)}

According to the theory of structural dissociation of the personality (Nijenhuis et al. 2002; Van der Hart et al. 2006), there is a dimension of complexity of the involved dissociation. In PTSD and simple sensorimotor dissociative disorders, there is generally one APN and one EP that can be rudimentary. Complex PTSD and complex sensorimotor disorders often involve 
one ANP and more than one EP that in minor DID can become quite elaborate. Major DID, finally, is the most complex form with commonly more than one ANP and more than one EP that also can take full executive control. The theory also holds that given lower integrative capacity in childhood, childhood adversity should be associated with more severe dissociative symptoms than adversity in adulthood.

If the theory is correct,

--dissociative symptoms should be correlated with reported and actual traumatization;

--dissociative reactions should be elicited by adverse events, but these events should not be the only causal factor;

--mental disorders (say, complex PTSD and DID) associated with childhood adversity should be characterized by more severe dissociative symptoms than mental disorders (say, simple PTSD) that pertain to adult traumatization;

--the severity of cognitive-emotional and sensorimotor dissociative symptoms should be proportional to the complexity of the dissociative disorder, so that there should be increasing severity of dissociative symptoms from healthy controls, simple PTSD, complex PTSD, minor DID and, finally, major DID;

--intrusions should not be limited to visual images, but also pertain to other characteristic of EPs.

\section{Cognitive-emotional dissociative symptoms: a dimension of severity}

\subsection{Relationship to adverse events}

A recent review (Carlson et al. 2012) documented that cognitive-emotional dissociative symptoms are moderately related to adverse event exposure and the severity of these events.

PTSD patients who were traumatized as children have more severe cognitive-emotional dissociation symptoms than PTSD patients who were traumatized as adults (Dancu et al. 1996; Ginzburg et al. 2006; Schafer et al. 2009). Among individuals with substance abuse, those with high cognitive-emotional dissociative symptoms had more trauma-related symptoms and childhood histories of emotional abuse and physical neglect than those with lesser dissociative symptoms (Najavits and Walsh 2012). The severity of cognitive-emotional dissociative symptoms was positively associated with experience of childhood sexual abuse and PTSD symptoms, particularly hyperarousal (Kamen et al. 2012). Adolescents who experienced physical and/or sexual maltreatment, whether emotionally neglected or not, reported significantly more symptoms of PTSD, dissociative amnesia, depersonalization and derealization, negative mood, and anhedonia than adolescents who experienced only neglect (Wechsler-Zimring and Kearney 2011).

A host of retrospective studies show that individuals with dissociative symptoms report a history of adverse events. These studies are consistent with longitudinal prospective studies showing that there is a relationship between early childhood traumatization and dissociative symptoms many years later (e.g., Diseth 2006; Trickett et al. 2011). These studies have also documented a relationship between disorganized attachment and dissociative symptoms two 
decades later (Ogawa et al. 1997), and disorganized attachment is common among traumatized children (Cyr et al. 2010).

\subsection{Peritraumatic dissociation}

Cognitive-emotional dissociative symptoms can emerge during and following adverse event remain high thereafter (Carlson et al. 2012). This peritraumatic dissociation is an important predictor of PTSD (e.g., Baranyi et al. 2010; Van der Hart et al. 2008).

\subsection{Relationship to PTSD symptoms}

Cognitive-emotional symptoms are consistently and strongly related to DSM-IV PTSD symptoms (Carlson et al. 2012). For example, anger and dissociative symptoms statistically predicted PTSD, hyperarousal, and avoidance/numbing severity, and dissociative symptoms predicted intrusive severity (Kulkarni et al. 2012). Cognitive-emotional and sensorimotor dissociative symptoms correlated with PTSD symptoms in a variety of populations (e.g., Schild and Dalenberg 2012).

\subsection{Relationship with disorder complexity}

Simple PTSD is associated with moderate to dissociative cognitive-emotional symptoms (Amdur and Liberzon 1996; Nejad and Farahati 2007). These symptoms are more severe in complex PTSD (Zucker et al. 2006). They are even more severe in minor DID, and reach their summit in major DID (Frischholz et al. 1990; Nijenhuis et al. 1999).

Minor and major DID involve a different 'type of dissociation' than other mental disorders and mental health (Rodewald et al. 2011). This difference may be due to the fact that the personality of mental healthy individuals and individuals with other mental disorders is not divided in two or more dissociative conscious subsystems (Nijenhuis and Van der Hart 2011). As might be expected, patients with depersonalization and derealization in addition to the standard PTSD symptoms that include positive dissociative symptoms report more dissociative symptoms than patients without serious depersonalization and derealization symptoms (Wolf et al. 2012). Furthermore, PTSD is the most prevalent comorbidity in minor and major DID (Boon and Draijer 1993; Rodewald et al. 2011). The comorbidity profiles of patients with DID as well as PTSD are very similar as well and different from patients with depression and anxiety disorders.

\subsection{Types of intrusion}

Intrusions are not limited to visual impressions. For example, hearing voices is fairly common in PTSD, and is recognized as a dissociative symptom in this disorder (Andrew et al. 2008; Brewin and Patel 2010).

Two cautionary notes must be made. One concern is that not all cognitive-emotional 
symptoms that are regarded as dissociative symptoms (e.g., derealization) necessarily reflect the existence of dissociative parts of the personality. The second is that most studies of dissociative symptoms disregard sensorimotor dissociative symptoms.

\section{Sensorimotor dissociative symptoms: another dimension of severity}

\subsection{Conversion}

Whereas sensorimotor dissociative symptoms are recognized and acknowledged in the DSM-5 section on dissociative disorders, sensorimotor dissociative disorders are classified as conversion disorder. The text on conversion disorder describes sensorimotor dissociative symptoms as conversion symptoms, but does not explain why or how conversion symptoms would differ from sensorimotor dissociative phenomena. The authors of DSM-5 have rejected conceptually and empirically founded proposals to rename and recategorize DSM-IV conversion disorder as somatoform or sensorimotor dissociative disorder (Brown et al. 2007; Nijenhuis 2004). Had they followed the suggestion, DSM5 would have been in line with ICD-10 (WHO 1992) that more consistently categorizes conversion disorder as dissociative disorders of movement and sensation (WHO 1992).

Sensorimotor dissociative symptoms remain underemphasized in DSM-5, and in the literature more generally. For example, the description of major DID mainly addresses cognitive-emotional dissociative symptoms. DSM-5 does not reflect consistent empirical evidence that the disorder is in equal measure characterized by sensorimotor dissociative symptoms such as analgesia, anesthesia, and body stiffening or paralysis and motor inhibitions (negative) and intruding pain, body sensations and perceptions, and body movements (positive) (see below).

\subsection{Relationship to adverse events}

Analgesia, anesthesia and motor stiffening (freezing) and paralysis (tonic immobility) are components of mammalian defensive reactions to physical threat and threat to life. These symptoms thus suggest a causal relationship with this adversity. Indeed, sensorimotor dissociative symptoms were moderately to strongly correlated with reported adverse events, and in particular threat to the body and life itself, in every study with the Somatoform Dissociation Questionnaire (SDQ-20; Nijenhuis et al. 1996; Nijenhuis 2009). The correlation was not mediated by absorption (Näring and Nijenhuis 2005), and existed in a variety of populations and cultures (e.g., Van Duijl et al. 2010). Diseth (2006) documented that chronic invasive medical traumatization in very early childhood was the only predictor of sensorimotor dissociation in adolescence.

\subsection{Peritraumatic sensorimotor dissociative symptoms}

Delayed recall of childhood sexual abuse is associated with peritraumatic sensorimotor dissociation and the severity of this abuse (Nijenhuis al. 2001). Particularly serious threat to the integrity of the body may evoke sensorimotor dissociative symptoms. 


\subsection{Relationship to PTSD symptoms and cognitive-emotional dissociative symptoms}

Sensorimotor dissociative symptoms strongly correlate with cognitive-emotional dissociative symptoms (Müller et al. 2010, 2013; Nijenhuis 2009), and PTSD symptoms (Nijenhuis et al. 2004; Schild and Dalenberg 2012). Cognitive-emotional and sensorimotor dissociative symptoms, PTSD symptoms, and reported adverse events were all negatively correlated with the hippocampal and parahippocampal gyrus volume (Ehling et al. 2008).

\subsection{Relationship with dissociative disorder complexity}

Sensorimotor dissociative symptoms are moderate in PTSD (Müller et al. 2010; EspiritoSanto and Pio-Abreu 2007) and sensorimotor dissociative disorders (Bru et al. 2009; EspiritoSanto and Pio-Abreu 2009; Nijenhuis 2009), marked in minor DID, and severe in major DID (Nijenhuis 2004, 2009). The symptoms are thus proportional to the complexity of the dissociation of the personality. Furthermore, the sensitivity and specificity of sensorimotor dissociative symptoms in the screening for DSM-IV dissociative disorders are very similar to those of screening instruments that mainly assess cognitive-emotional dissociative symptoms (Müller et al. 2013; Nijenhuis 2004).

\subsection{Intrusions}

Patients with dissociative disorders tend to be recurrently intruded by negative and positive sensorimotor dissociative phenomena. For example, an EP in pain can intrude an ANP. ANP may or may not recognize that the pain relates to the EP.

\subsection{Conclusion}

Phrased in terms of DSM-5, 'conversion symptoms' are as characteristic of dissociative disorders including PTSD as (cognitive-emotional) 'dissociative symptoms'. If only to avoid the confusing conclusion that dissociative disorders are primarily characterized by psychopathology ('conversion') that would belong to a different mental disorder ('conversion disorder'), it is better formulated that conversion symptoms are sensorimotor dissociative symptoms, and that conversion disorders are dissociative disorders.

\section{PTSD and DSM-5 dissociative disorders: shared structural brain abnormalities}

A history of child abuse is associated with deficits in brain volume, gray and white matter of several regions, most prominently the dorsolateral and ventromedial prefrontal cortex, but also hippocampus, amygdala, and corpus callosum (CC) (Hart and Rubia 2012). Diffusion tensor imaging (DTI) studies show evidence for deficits in structural interregional connectivity between 
these areas, suggesting neural network abnormalities (Hart and Rubia 2012).

PTSD as well as minor and major DID are associated with similar, though not identical volumetric brain abnormalities (Chalavi 2013; Reinders et al. 2014). Compared to healthy controls, both disorders involve similarly smaller gray matter volume for the whole-brain, and the frontal, temporal and insular cortices. However, DID patients had smaller hippocampal and larger caudate and pallidum volumes than healthy controls, and larger putamen and pallidum volumes than patients with PTSD.

There are also negative correlations between the degree of traumatization and the volume of the hippocampus structure and the frontal, parietal, temporal cortices and the total cortex (Chalavi 2013; Reinders et al. 2014). Further, hippocampal volume is progressively smaller in individuals who have been exposed to adverse events (Woon et al. 2010), PTSD (Chen and Shi 2011; Karl et al. 2006; Woon et al. 2010), minor DID (Ehling et al. 2008), and major DID (Chalavi 2013; Ehling et al. 2008; Reinders 2014; Vermetten et al. 2006). Hippocampal volume in minor and major DID were negatively correlated with cognitive-emotional and sensorimotor dissociative symptoms, PTSD symptoms, and reported chronic traumatization (Ehling et al. 2008). However it was not, or only weakly correlated with general psychopathology and fantasy proneness.

\section{PTSD and DSM-5 dissociative disorders: shared physiological abnormalities}

Schopenhauer intuited that the will relates to the depth of our brain. Consistent with this, Panksepp (1998) emphasizes that mammalian action/will systems have roots in the periaquaductal grey and adjacent brainstem structures, and have links with the emotional brain, also described as the limbic system.

If TSDP is a step in the right direction, the different epistemic person-perspectives of dissociative parts and the involved affects, behaviors, and cognitions (ideas) should be associated with particular patterns of brain activity (see table 1). For example, PTSD and DID patients have dissociative part-dependent increased, decreased, or unaltered heart rate when confronted with reminders of traumatizing events. 
Table 1. Reactions to reminders of traumatic experiences of prototypical ANPs, hyperaroused Fragile EPs (EP-Hyper), and hypoaroused Fragile EPs (EP-Hypo): several hypotheses

\begin{tabular}{|c|c|c|c|}
\hline & Mental and behavioral states & $\begin{array}{l}\text { Psychophysiological } \\
\text { states }\end{array}$ & Brain states \\
\hline ANP & $\begin{array}{l}\text { Emotionally numbed. } \\
\text { Bodily numbed. } \\
\text { Depersonalized. } \\
\text { Focused on wills of daily } \\
\text { life. } \\
\text { Behaviorally underengaged } \\
\text { in defense. }\end{array}$ & $\begin{array}{l}\text { No significant } \\
\text { changes in: } \\
\text { Heart rate; } \\
\text { Heart rate variability; } \\
\text { Blood pressure; } \\
\text { Some degree of } \\
\text { ventral vagal control }\end{array}$ & $\begin{array}{l}\text { General } \\
\text { underengagement } \\
\text { in cues. } \\
\text { More activation of } \\
\text { neocortical structures } \\
\text { such as medial } \\
\text { prefrontal cortex and } \\
\text { anterior cingulate, } \\
\text { and multimodal } \\
\text { association areas. }\end{array}$ \\
\hline EP-Hyper & $\begin{array}{l}\text { High emotionality. } \\
\text { Strong sensory reactions. } \\
\text { Behavioral engagement in } \\
\text { active kinds of mammalian } \\
\text { defense }\end{array}$ & $\begin{array}{l}\text { High heart rate. } \\
\text { Low heart rate } \\
\text { variability. } \\
\text { High blood pressure. } \\
\text { Other markers of } \\
\text { sympathetic nervous } \\
\text { system dominance. }\end{array}$ & $\begin{array}{l}\text { More activation of } \\
\text { brain stem, emotional } \\
\text { brain structures } \\
\text { such as amygdala, } \\
\text { basal ganglia, and } \\
\text { neocortical areas } \\
\text { such as insula and } \\
\text { sensorimotor cortex. }\end{array}$ \\
\hline ЕР-Нуро & $\begin{array}{l}\text { Low emotionality } \\
\text { Analgesia-anesthesia. } \\
\text { Paralysis. Low } \\
\text { consciousness. Out- } \\
\text { of-body phenomena } \\
\text { Behavioral engagement in } \\
\text { tonic immobility. }\end{array}$ & $\begin{array}{l}\text { Low heart rate. } \\
\text { Low heart rate } \\
\text { variability. Low } \\
\text { blood pressure. Other } \\
\text { markers of dorsal } \\
\text { vagal dominance. }\end{array}$ & $\begin{array}{l}\text { Extreme } \\
\text { underengagement in } \\
\text { cues. Involvement of } \\
\text { the periaquaductal } \\
\text { gray and the } \\
\text { basolateral amygdala. }\end{array}$ \\
\hline
\end{tabular}

Research supports the various hypotheses (Bremner et al. 1999a, b; Frewen and Lanius 2006; Hopperet al. 2007; Lanius et al. 2002, 2003, 2005, 2006, 2010, 2012; Wolf et al. 2012a, b). Osuch et al. 2001; Pissiota et al. 2002; Rauch et al. 1996; Reinders et al. 2006, 2012; Shin et al. 1999). Some PTSD patients become psychophysiologically hyperaroused and relive traumatic experiences. Others are not affected much, or become hypoaroused. Referring to our work (Nijenhuis et al. 1998a; Nijenhuis et al. 1998b; Nijenhuis et al. 2002), Frewen and Lanius (2006) proposed that hyperaroused reliving of traumatic experiences involves sympathetically related mammalian flight and freezing. They also concurred with us that detached responding can relate to tonic immobility and/or emotional numbing as a means of avoiding traumatic memories.

Bremner (1999) and Lanius et al. (2010, 2012) suggested that these different reaction patterns involve two subtypes of PTSD. Individuals with the "reexperiencing/hyperarousal subtype" become hyperaroused and tend to relive traumatic experiences when confronted with reminders of these experiences. Those with the "dissociative subtype" of PTSD - the current DSM-5 
PTSD with dissociative symptoms--remain physiologically stable or become hypoaroused and subjectively detached.

The psychophysiological reactions of patients with DID to descriptions of traumatizing events depend on ANP/EP (Reinders et al. 2006, 2012). Fearful EPs for whom the trauma script pertained to a personal event responded with increased heart rate and systolic blood pressure. ANPs who had not personalized the involved memory remained mentally and physiologically unaffected. Heart rate of EPs engaging in tonic immobility in psychotherapy sessions remained unaltered or dropped (Nijenhuis, unpublished data). They became absent-minded, and emotionally and physically numb. Some also lost muscle tone.

\section{PTSD and DSM-5 dissociative disorders: shared functional brain abnormalities}

DID involves biopsychosocial differences for ANP and EP in response to trauma-related cues that are inexplicable as effects of suggestion, fantasy, and motivated role playing (Hermans et al. 2006; Reinders et al. 2003, 2006, 2012; Schlumpf et al. 2013). PTSD patients can respond to these cues with hyperarousal to the point of full-blown flashbacks, or hypoaroused depersonalization/derealization and emotional detachment (i.e., 'PTSD with dissociative symptoms'). On TSDP, hyperarousal involves one or more hyperaroused Fragile EPs, and hypoarousal one or more ANPs or Fragile EPs in tonic immobility (table 1). PTSD and DID patients have largely similar ANP-dependent and EPdependent neural reaction patterns to reminders of their traumatic experiences (table 2).

Table 2. Profound overlap in brain area activation in hyperaroused (Fragile EPS) and nonaroused or hypoaroused (ANPs or Fragile EPS) patients with PTSD and DID

\begin{tabular}{|l|l|l|}
\hline $\begin{array}{l}\text { Disorder, experimental } \\
\text { condition }\end{array}$ & Brain area activation & Studies \\
\hline $\begin{array}{l}\text { 8.1. Hyperactivation: EP in } \\
\text { PTSD }\end{array}$ & $\begin{array}{l}\text { In italics, shared brain area hyperactivation in } \\
\text { PTSD-EP (8.1) and DID-EP (8.2) }\end{array}$ & \\
\hline $\begin{array}{l}\text { Exposure to reminders of } \\
\text { traumatizing events: (PTSD } \\
\text { as hyperaroused EP) - (HC) }\end{array}$ & $\begin{array}{l}\text { + amygdala } \\
\text { +anterior paralimbic regions (e.g., insula) } \\
\text { +R sensorimotor cortex, BA 1-4, 6 } \\
\text { +cerebellum, cerebellar vermis } \\
\text { +brainstem: periaquaductal grey }\end{array}$ & $\begin{array}{l}\text { Frewen \& Lanius 2006; } \\
\text { Lanius, Bluhm, Lanius, \& } \\
\text { Pain 2006; Lanius et al. } \\
\text { 2010; Pissiota et al. 2002; } \\
\text { Rauch, Shin, \& Phelps 2006; } \\
\text { Schmahl, Lanius, Pain, \& } \\
\text { Vermetten 2010 }\end{array}$ \\
\hline $\begin{array}{l}\text { Positive correlations with } \\
\text { PTSD flashback intensity }\end{array}$ & $\begin{array}{l}\text { brainstem, } \\
\text { lingula, } \\
\text { LR insula } \\
\text { R basal ganglia, putamen } \\
\text { L hippocampal and perihippocampal } \\
\text { regions } \\
\text { L somatosensory regions } \\
\text { cerebellar regions }\end{array}$ & \\
\hline
\end{tabular}


Table 2. Continued

\begin{tabular}{|c|c|c|}
\hline 8.2. Hyperactivation: EP in DID & & \\
\hline $\begin{array}{l}\text { Exposure to personal trauma } \\
\text { memory in DID: (EP) - } \\
\text { (ANP) }\end{array}$ & $\begin{array}{l}\text { +RL insula } \\
\text { +RL amygdala } \\
\text { +RL basal ganglia, caudate } \\
\text { +R lateral fissure/postcentral gyrus: } \\
\text { somatosensory cortex SII, BA43 } \\
\text { +inferior temporal gyrus, BA } 20 \\
\text { +middle temporal gyrus, BA } 21 \\
\text { + } \mathrm{L} \text { cerebellum, ventral-medial and lateral part }\end{array}$ & Reinders et al. 2003, 2006 \\
\hline $\begin{array}{l}\text { Exposure to personal trauma* } \\
\text { memory script: EP and ANP } \\
\text { in DID versus EP and ANP } \\
\text { simulating, high fantasy prone } \\
\text { HC: } \\
\text { (DID as EP - DID as ANP) - } \\
\text { (HC as EP - HC as ANP) }\end{array}$ & $\begin{array}{l}\text { + } \mathrm{L} \text { orbitofrontal cortex, BA11 } \\
+\mathrm{R} \text { postcentral gyrus, } \mathrm{BA} 43 \\
+\mathrm{L} \text { amygdala } \\
+\mathrm{RL} \text { basal ganglia, caudate } \\
+\mathrm{L} \text { basal ganglia, putamen } \\
+\mathrm{L} \text { cerebellum }\end{array}$ & Reinders et al. 2012 \\
\hline $\begin{array}{l}\text { DID as EP versus EP- } \\
\text { simulating high fantasy prone } \\
\text { HC: } \\
\text { (EP exposure to trauma* } \\
\text { memory script) - (EP exposure } \\
\text { to neutral memory script) }\end{array}$ & $\begin{array}{l}\text { +L insula } \\
+\mathrm{R} \text { inferior temporal gyrus, BA } 20 \\
+\mathrm{R} \text { basal ganglia, caudatus, dorsal/ } \\
\text { dorsal-lateral } \\
\text { +L basal ganglia, caudatus, tail } \\
\text { +L basal ganglia, putamen }\end{array}$ & Reinders et al. 2012 \\
\hline $\begin{array}{l}\text { 8.3. Hypoactivation: ANP } \\
\text { (or EP tonic immobility in } \\
\text { some cases) in PTSD }\end{array}$ & $\begin{array}{l}\text { In bold, shared brain area activation in } \\
\text { PTSD as ANP (or EP in total submission) } \\
\text { and relatively deactivated brain areas for } \\
\text { PTSD as EP (8.3), brain area activation in } \\
\text { DID as ANP, and as EP neutral memory } \\
(8.4) \text {, and depersonalization disorder }(8.5)\end{array}$ & \\
\hline $\begin{array}{l}\text { Exposre to trauma-related } \\
\text { cues: (PTSD hypoarousal, } \\
\text { probably in most cases as } \\
\text { ANP) - (HC) }\end{array}$ & $\begin{array}{l}\text { + superior and middle temporal gyri, BA } 38 \\
\text { +inferior, middle, and superior frontal } \\
\text { gyrus (e.g., BA 47) } \\
\text { +R medial frontal gyrus, BA 10 } \\
\text { +medial prefrontal cortex, BA 9 } \\
\text { +R anterior cingulate gyrus, BA 24, } 32 \\
\text { +ventral prefrontal cortex BA } \\
\text { +insula } \\
\text { +parietal lobe, BA } 7 \\
\text { +RL occipital lobe, cuneus BA } 19 \\
\text {-dorsomedial prefrontal regions } \\
\end{array}$ & $\begin{array}{l}\text { Felmingham et al. 2008; } \\
\text { Frewen \& Lanius 2006; } \\
\text { Lanius et al. 2002; Schmahl } \\
\text { et al. } 2010\end{array}$ \\
\hline $\begin{array}{l}\text { Exposure to reminders of } \\
\text { traumatizing events: } \\
\text { (PTSD as hyperaroused } \\
\text { EP) versus (HC), relative } \\
\text { deactivation for PTSD as } \\
\text { hyperaroused EP }\end{array}$ & $\begin{array}{l}\text {-ventromedial prefrontal regions } \\
\text {-anterior cingulate, BA 32 } \\
\text {-L inferior frontal gyrus, BA } 47 \\
\text {-medial frontal gyrus, BA 10, } 11 \\
\text {-L middle temporal cortex } \\
\text {-R retrosplenial cortex, BA 21, 29, 30, } \\
\text { and in part } 23 \\
\text {-parietal cortex, BA 40 } \\
\text {-occipital visual association cortex, BA } 19 \\
\text {-R inferior temporal gyrus, BA } 20 \\
\text {-R hippocampus } \\
\text {-thalamus }\end{array}$ & $\begin{array}{l}\text { Frewen \& Lanius 2006; } \\
\text { Lanius et al. 2006; Lanius et } \\
\text { al. 2010; Pissiota et al. 2002; } \\
\text { Rauch et al. 2006; Schmahl } \\
\text { et al. } 2010\end{array}$ \\
\hline
\end{tabular}


Table 2. Continued

\begin{tabular}{|c|c|c|}
\hline $\begin{array}{l}\text { Negative correlations with } \\
\text { PTSD flashback intensity }\end{array}$ & $\begin{array}{l}\text { LR dorsolateral prefrontal cortex } \\
\mathrm{R} \text { fusiform cortex (occipitotemporal } \\
\text { cortex) } \\
\mathrm{R} \text { middle temporal cortex }\end{array}$ & Osuch et al. 2001 \\
\hline \multicolumn{3}{|l|}{$\begin{array}{l}\text { 8.4. Hypoactivation: ANP } \\
\text { in DID }\end{array}$} \\
\hline $\begin{array}{l}\text { Exposure to trauma memory } \\
\text { script in DID: } \\
(\text { ANP) - (EP) }\end{array}$ & 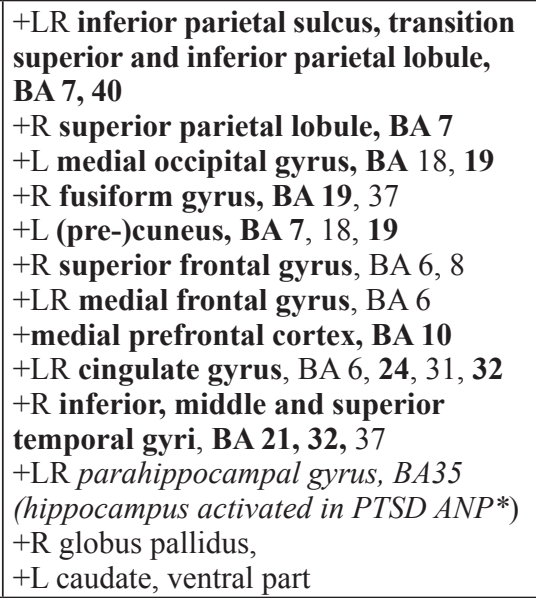 & Reinders et al. 2003, 2006 \\
\hline $\begin{array}{l}\text { Exposure to trauma* memory } \\
\text { script } \\
\text { ([DID as ANP }]-[D I D \text { as } \\
\text { EP] }-([\text { high fantasy prone } \\
\text { HC as ANP }-[\text { high fantasy } \\
\text { prone } \mathrm{HC} \text { as EP]) }\end{array}$ & 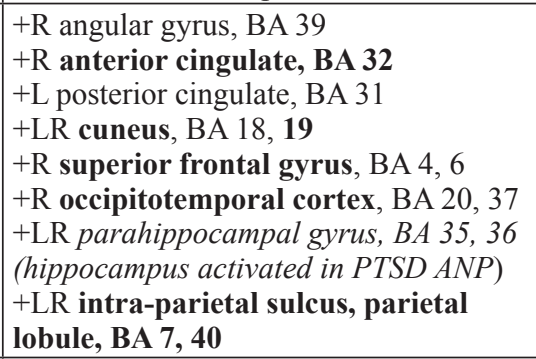 & Reinders et al. 2012 \\
\hline $\begin{array}{l}\text { Exposure to neutral and } \\
\text { trauma* memory script: } \\
\text { ([DID as EP, neutral script] } \\
\text { - [DID as EP trauma script]) } \\
\text { - ([high fantasy prone HC } \\
\text { as EP, neutral script[ - [high } \\
\text { fantasy prone HC as EP, } \\
\text { trauma* script] })\end{array}$ & $\begin{array}{l}\text { +L cuneus, BA } 18,19 \\
\text { +R occipito-temporal sulcus, BA 20, } 37 \\
\text { +R intra parietal sulcus, BA 7, } 40 \\
\text { + } \mathrm{L} \text { precuneus, BA } 7,31 \\
\text { + } \mathrm{R} \text { middle temporal gyrus, BA } 21\end{array}$ & Reinders et al. 2012 \\
\hline \multicolumn{3}{|l|}{ 8.5. Depersonalization disorder } \\
\hline $\begin{array}{l}\text { Depersonalization disorder } \\
\text { versus HC }\end{array}$ & $\begin{array}{l}\text { +LR parietal cortex, BA 7B, } 39 \\
\text { +L occipital cortex, BA } 19 \\
\text {-R superior and middle temporal gyri, BA } \\
\text { 21, } 22 \\
\text { Dissociation and depersonalization } \\
\text { scores among the subjects with } \\
\text { depersonalization disorder were } \\
\text { significantly positively correlated with } \\
\text { metabolic activity in BA 7B }\end{array}$ & Simeon et al. 2000 \\
\hline
\end{tabular}


Table 2. Continued

\begin{tabular}{|l|l|l|}
\hline $\begin{array}{l}\text { 8.6. Masking paradigm } \\
\text { PTSD }\end{array}$ & $\begin{array}{l}\text { Overlap between PTSD and DID is } \\
\text { indicated by underlining }\end{array}$ & \\
\hline $\begin{array}{l}\text { Masked images of adverse } \\
\text { and benign events/cues: } \\
\text { within PTSD and between } \\
\text { PTSD and HC }\end{array}$ & $\begin{array}{l}\text { +L parahippocampal gyrus } \\
\text { +L hippocampus, tail }\end{array}$ & Sakamoto et al. 2005 \\
\hline 8.7. Masking paradigm DID & & \\
\hline $\begin{array}{l}\text { Angry faces as well as neutral } \\
\text { faces: } \\
\text { (DID as EP) - (DID as ANP) }\end{array}$ & Schlumpf et al. 2013 \\
$\begin{array}{l}\text { Neutral faces: } \\
\text { (DID as EP) - (EP simulating } \\
\text { actors) }\end{array}$ & $\begin{array}{l}\text { +L brain stem } \\
\text { +R parahippocampal gyrus } \\
\text { +LR middle frontal gyrus } \\
\text { +R middle temporal gyrus } \\
\text { +L presupplementary motor area } \\
\text { +LR precentral gyrus (primary motor } \\
\text { area) } \\
\text { +posterior middle cingulate/dorsal } \\
\text { posterior cingulate } \\
\text { +R dorsal medial prefrontal cortex } \\
\text { +R middle temporal gyrus } \\
\text { +L superior temporal gyrus } \\
\text { +R lateral occipital cortex, inferior part } \\
\text { +R occipital pole }\end{array}$ & \\
& \\
\end{tabular}

General remarks: based on the reasons provided in this article, hyperarousal in PTSD involves an intruding hyperaroused EP or a switch to a hyperaroused EP, and nonarousal or hypoarousal in PTSD pertains in most cases to a mentally avoidant ANP, or to an intruding EP in total submission, or to a switch to that EP. In the case of a switch, one dissociative part takes executive control, whereas one or more other dissociative parts become deactivated. In the case of an intrusion, one dissociative part strongly influences another dissociative part

ANP: apparently normal part of the personality

EP: emotional part of the personality

DID: dissociative identity disorder. In Reinders et al. (2003, 2006, 2012) and Schlumpf et al. (2013): all women

HC: mentally healthy controls

HC in Reinders et al., 2012: extremely fantasy prone women

HC in Schlumpf et al., 2013: female actors

L: left hemisphere

$\mathrm{R}$ : right hemisphere

*Trauma memory scripts with respect to HC in Reinders et al. (2012) involved the worst adverse events HC were willing to share with the investigators

\section{\#8.1 and 8.2: Hyperaroused EP in PTSD and DID}

Confronted with reminders of traumatizing events, hyperaroused EP in PTSD (8.1) and DID patients as EP (8.2) activate strikingly similar parts of the brain, including the amygdala, insula, 
parts of the basal ganglia (caudate, putamen), sensory cortex, inferior and middle temporal gyrus, and portions of the cerebellum. These structures have major roles in unconditioned and conditioned emotional and motor defensive reactions to actual or perceived threat cues, as well as in evaluations of (alarming) bodily sensations and states.

This neural hyperreactivity is linked with underactivated frontal cortical areas, and suggests a lack of inhibition of conditioned emotional reactions to former threat (e.g., Rauch et al. 2006). Underactivation of the hippocampal regions may indicate a lack of context evaluation (Rauch et al. 2006) that contributes to persevering alarm reactions to reminders of traumatizing events.

\section{\#8.3 - 8.5: Hypoarousal in PTSD, DID, and depersonalization disorder}

PTSD patients who react to reminders of traumatizing events with depersonalization/ derealization and emotional numbing in PTSD had brain activation patterns (8.3) that match those for ANP in DID patients (8.4). The structures include frontal (BA 9, 10, 24, 32), parietal (BA 7, 40), occipital (BA 19), and hippocampal regions. Many of these are activated during emotional memory suppression in mentally healthy individuals such as frontal areas (BA 4, 6, 8, 10/47), anterior cingulate cortex (BA 32), and intraparietal sulcus (BA 7, 40)(see Reinders et al. 2006). In patients with depersonalization disorder, BA 7 and 19 are also more activated than in healthy controls.

\section{\#8.6 - 8.7: Masked reminders of traumatizing events in PTSD and DID}

Sakamoto et al. (2005) exposed PTSD patients to masked images of traumatizing events, and performed a whole brain analysis (other masking studies of PTSD did not include this analysis) (8.6). Activation of the ventral frontoparietal network associated with visual attention processing was attenuated. Their left hippocampal area associated with episodic and autobiographical memory was abnormally easily activated. This pattern "corresponds well to the clinical characteristics of PTSD, in which even slight traumatic stimuli tend to induce intrusive recollection or flashbacks, despite a general decrease in attention and ability to concentrate" (p. 813).

Hyperaroused EPs in DID also activated the parahippocampal gyrus in reaction to masked neutral faces (8.7). This area and the hippocampus were correlated with flashback intensity in hyperaroused PTSD patients (Osuch et al. 2001, see 8.1), and are implicated in the recall of autobiographical memories. Consistent with clinical observations, neutral faces may be threatening and ambiguous to EPs. The masked faces seem to elicit an instant search for meaning as is suggested by the activation of the temporal pole of the superior temporal gyrus, a part of a semantic system (Schlumpf et al. 2013).

Areas more activated for EPs in DID as compared to EPs-simulating actors included structures with functions in early phases of face perception, and motor areas supporting defensive reactions to perceived threat. Comparing ANPs in DID and EPs in the actors yielded a similar but less pronounced pattern of neural activation. ANPs' lesser involvement in consciously perceived trauma-related cues (Reinders et al. 2003, 2006, 2012) could have roots in these parts' subdued preconscious reactivity to trauma-related cues. 


\subsection{Conclusion}

There is major commonality at the level of the brain between hyperaroused reenactment of traumatizing events in PTSD - which according to the present analysis involves EPs - and EPs in DID who engage in active mammalian defense to reminders of traumatic experiences and to perceived threat. The match pertains to supraliminally and subliminally presented cues. The commonality also exists for ANP in DID, hypoarousal in PTSD, and depersonalization disorder.

\section{Treatment}

The treatment of PTSD and more complex dissociative disorders entails the integration and realization of nonsymbolized traumatic memories that individuals reenact as EPs and avoid as ANPs. With this progress, dissociative parts can generally integrate as well. The ability to integrate and realize depends on the severity/duration/timing of traumatization, integrative capacity, affectregulation skills, social support, and phobias of traumatic memories, dissociative parts, attachment, attachment loss, bodily feelings, and affect. When the constellation of these factors is favorable, integrative actions can proceed rather quickly. The more unfavorable it is, the more complex and time-consuming therapy will be (Van der Hart et al. 2006).

\section{Parsimony}

There are major ontological, epistemic, conceptual, theoretical (1-3), and empirical reasons (4-9) for understanding and classifying any type of PTSD as a dissociative disorder. This tenth ground is parsimony and consistency. Studies showing different biopsychosocial reactions in PTSD to actual or perceived threat cues over time would further strengthen this position. These alternations are clinically observed (Lanius et al. 2010) and theoretically formulated in TSDP.

The terms 'PTSD with dissociative symptoms' and 'dissociative subtype of PTSD' must be rejected given the involved contradictory definition and use of the term 'dissociation', unclear distinctions between negative and positive dissociative symptoms, and absent formulations what dissociative symptoms are symptoms of. Recognizing that any type of PTSD involves a dissociation of the personality and its implied cognitive-emotional and sensorimotor manifestations, and renaming the subtype as 'PTSD with marked negative dissociative symptoms' solves these problems.

The DSM-5 recognizes sensorimotor dissociative symptoms, but also uses the terms 'conversion symptoms/disorders', and does not define how conversion and sensorimotor dissociation differ. Because they involve identical phenomena, the resolution is to rename and reclassify conversion symptoms/disorders as sensorimotor dissociative symptoms/disorders.

On TSDP, dissociative disorders vary along a continuum of severity of dissociation of the personality as a whole biopsychosocial system in different conscious subsystems. Personality involves ever changing, dynamic configurations of brain, body, and environment. Intrinsically embrained, embodied and environmentally embedded, the system can become divided in conscious subsystems in the context of adverse embedded events. The study of the injury that trauma is 
requires all epistemic perspectives, since the meaning of third-person perspective findings can only be ascertained in relationship with the studied individuals' pluriform person perspectives. The complication is that traumatized individuals experience and conceive more than one 'I', 'I-me, myself, mine', and 'I-You' perspectives, as Pierre Janet taught.

\section{Riassunto}

\section{DIECI RAGIONI PER CONCEPIRE E CLASSIFICARE IL DISTURBO DA STRESS POST- TRAUMATICO COME UN DISTURBO DISSOCIATIVO}

Parole chiave: DSPT, disturbi dissociativi, dissociazione della personalità, sintomi dissociativi emotivocognitivi, sintomi dissociativi sensomotori, psicofisiologia, neurobiologia.

Il DSM-5 include un sottotipo di DSPT "con sintomi dissociativi". Tuttavia, come sarà discusso e presentato in questo articolo, ci sono valide ragioni concettuali, teoriche, empiriche e cliniche per comprendere e classificare ogni forma di DSPT come un disturbo dissociativo. I motivi concettuali riguardano i principi filosofici raramente discussi o considerati nell'ambito della psicotraumatologia. Le basi teoriche riguardano in particolare la comprensione della dissociazione come una divisione della personalità e del sistema biopsicosociale in due o più sistemi consci. Le ragioni empiriche includono la presenza nel DSPT di sintomi

dissociativi sensomotori ed emotivo-cognitivi (ad esempio, manifestazioni di una dissociazione della personalità): alle quali si aggiungono i pirincipali aspetti neuronali funzionali e strutturali in comune fra il DSPT e i disturbi dissociativi complessi. Da un punto di vista clinico, c'è una stretta corrispondenza a livello sia della valutazione sia del trattamento. DSPT e disturbo dissociativo dell'identità possono essere concepiti con parsimonia come forme maggiori o minori di una dissociazione della personalità, come Pierre Janet avrebbe affermato.

\section{Abstract}

Key words: PTSD, dissociative disorders, dissociation of the personality, cognitive-emotional dissociative symptoms, sensorimotor dissociative symptoms, psychophysiology, neurobiology

DSM-5 includes a subtype of PTSD 'with dissociative symptoms'. However, as presented and discussed in this article, there are solid conceptual, theoretical, empirical, and clinical reasons to comprehend and classify any form of PTSD as a dissociative disorder. The conceptual grounds pertain to philosophical principles seldom discussed or realized in the field of psychotraumatology. The theoretical grounds particularly involve the understanding of dissociation as a division of the personality as a whole biopsychosocial system in two or more conscious subsystems. Empirical reasons include the presence of cognitive-emotional and sensorimotor dissociative symptoms - i.e., manifestations of a dissociation of the personality--in PTSD.

There are also major structural and functional neural commonalities between PTSD and complex dissociative disorders. Clinically, there is close correspondence at the level of assessment and treatment. PTSD and dissociative identity disorder can be parsimoniously conceived as minor and major forms of personality dissociation, as Pierre Janet would have avowed.

\section{References}

Amdur R, Liberzon I (1996). Dimensionality of dissociation in subjects with PTSD. Dissociation 9, 118-124. American Psychiatric Association (1994). Diagnostic and Statistical Manual of Mental Disorders IV. American 


\section{Ellert R.S. Nijenhuis}

Psychiatric Association, Washington, DC.

American Psychiatric Association (2013). Diagnostic and statistical manual of mental disorders, fifth edition $D S M-V$. American Psychiatric Publishing, Washington D.C./London.

Andrew EM, Gray NS, Snowden RJ (2008). The relationship between trauma and beliefs about hearing voices: A study of psychiatric and non-psychiatric voice hearers. Psychological Medicine 38, 10, 1409-1417.

Badour CL, Bown S, Adams TG, Bunaciu L, Feldner, M.T. (2012). Specificity of fear and disgust experienced during traumatic interpersonal victimization in predicting posttraumatic stress and contamination-based obsessive-compulsive symptoms. Journal of Anxiety Disorders 26, 5, 590-598.

Baranyi A, Leithgob O, Kreiner B, Tanzer K, Ehrlich G, Hofer HP, et al. (2010). Relationship between posttraumatic stress disorder, quality of life, social support, and affective and dissociative status in severely injured accident victims 12 months after trauma. Psychosomatics 51, 3, 237-247.

Bitbol M (2008). Is consciousness primary? NeuroQuantology 6, 1, 53-72.

Boon S, Draijer N (1993). Multiple personality disorder in The Netherlands: A clinical investigation of 71 patients. American Journal of Psychiatry 150, 3, 489-494.

Braude SE (1995). First person plural: Multiple personality and the philosophy of mind. Rowman and Littlefield, Lanham.

Bremner JD (1999). Acute and chronic responses to psychological trauma: Where do we go from here? American Journal of Psychiatry 156, 349-351.

Bremner JD, Staib L, Kaloupek D, Southwick SM, Soufer R, Charney DS (1999b). Neural correlates of exposure to traumatic pictures and sound in Vietnam combat veterans with and without posttraumatic stress disorder: A positron emission tomography study. Biological Psychiatry 45, 806-816.

Brett EA (1996). The classification of posttraumatic stress disorder. In BA van der Kolk, AC McFarlane, L Weisaeth (Eds.) Traumatic stress: The effects of overwhelming experience on mind, body, and society, pp. 117-128. Guilford Press, New York.

Brett EA, Spitzer RL, Williams JB (1988). DSM-III-R criteria for posttraumatic stress disorder. American Journal of Psychiatry 145,10, 1232-1236.

Brewin CR, Patel T (2010). Auditory hallucinations in United Kingdom war veterans and civilians with posttraumatic stress disorder. Journal of Clinical Psychiatry 71, 4, 419-425.

Brown RJ, Cardeña E, Nijenhuis ERS, Sar V, Van der Hart O (2007). Should conversion disorder be reclassified as a dissociative disorder in DSM-V? Psychosomatics 48, 5, 369-378.

Bru M, Santamaria M, Coronas R, Cobo JV (2009). Dissociative disorder and traumatic events: A study of Spanish population. Actas Esp Psiquiatr 37, 4, 200-204.

Carlson EB, Dalenberg C, McDade-Montez E (2012). Dissociation in Posttraumatic Stress Disorder Part I: Definitions and review of research. Psychological trauma: theory, research, practice, and policy. Advance online publication. doi: 10.1037/a0027748

Chalavi S (2013). The traumatized brain: Gray and white matter morphology in dissociative identity disorder and PTSD. Dissertation Rijks Universiteit Groningen, Netherlands

Charcot J-M (1889). Clinical lectures on diseases of the nervous system. Volume III. New Sydenham Society, London.

Chen J, Shi S (2011). A review of neuroimaging studies of anxiety disorders in China. Neuropsychiatric Disease and Treatment 7, 241-249.

CyrC, EuserEM, Bakermans-Kranenburg MJ, Van IJzendoorn MH(2010). Attachment security and disorganization in maltreating and high-risk families: A series of meta-analyses. Developmental Psychopathology 22, 1, 87108.

Dancu CV, Riggs DS, Hearst-Ikeda D, Shoyer BG, Foa EB (1996). Dissociative experiences and posttraumatic stress disorder among female victims of criminal assault and rape. Journal of Traumatic Stress 9, 2, 253-267.

Dewhurst K (1966). Sir Thomas Sydenham: His life and original writings. University of California Press, Berkeley/Los Angeles.

Diseth TH (2006). Dissociation following traumatic medical treatment procedures in childhood: A longitudinal follow-up. Developmental Psychopathology 18, 1, 233-251.

Draijer N, Langeland W (1999). Childhood trauma and perceived parental dysfunction in the etiology of 
dissociative symptoms in psychiatric inpatients. American Journal of Psychiatry 156, 3, 379-385.

Ehling T, Nijenhuis ER, Krikke AP (2008). Volume of discrete brain structures in complex dissociative Ten reasons for conceiving and classifying posttraumatic stress disorder as a dissociative disorder disorders: Preliminary findings. Progress in Brain Research 167, 307-310.

Espirito Santo H, Pio Abreu JL (2007). Dissociative disorders and other psychopathological groups: Exploring the differences through somatoform dissociation questionnaire (SDQ-20). Revista Brasiliera Psiquiatria 29, 354-358.

Espirito-Santo H, Pio-Abreu JL (2009). Psychiatric symptoms and dissociation in conversion, somatization and dissociative disorders. Australian and New Zealand Journal of Psychiatry 43, 3, 270-276.

Felmingham K, Kemp AH, Williams L, Falconer E, Olivieri G, Peduto A, et al. (2008). Dissociative responses to conscious and non-conscious fear impact underlying brain function in post-traumatic stress disorder. Psychological Medicine 38, 12, 1771-1780.

Frewen PA, Lanius RA (2006). Toward a psychobiology of posttraumatic self-dysregulation: Reexperiencing, hyperarousal, dissociation, and emotional numbing. Annals New York Academy of Sciences 1071, 110-124.

Frischholz EJ, Braun BG, Sachs RG, Hopkins L, et al. (1990). The Dissociative Experiences Scale: Further replication and validation. Dissociation: Progress in the Dissociative Disorders 3, 3, 151-153.

Ginzburg K, Koopman C, Butler LD, Palesh O, Kraemer HC, Classen CC, et al. (2006). Evidence for a dissociative subtype of post-traumatic stress disorder among help-seeking childhood sexual abuse survivors. Journal of Trauma and Dissociation 7, 2, 7-27.

Hart H, Rubia K (2012). Neuroimaging of child abuse: A critical review. Front Hum Neurosci 6, 52.

Hermans EJ, Nijenhuis ER, Van Honk J, Huntjens RJ, Van der Hart O (2006). Identity state-dependent attentional bias for facial threat in dissociative identity disorder. Psychiatry Research 141, 233-236.

Hopper JW, Frewen PA, van der Kolk BA, Lanius RA (2007). Neural correlates of reexperiencing, avoidance, and dissociation in PTSD: Symptom dimensions and emotion dysregulation in responses to script-driven trauma imagery. Journal of Traumatic Stress 20, 5, 713-725.

Horowitz MJ (1976). Stress response syndromes. J. Aronson, NY.

Huntjens RJ, Postma A, Peters ML, Woertman L, Van der Hart O (2003). Interidentity amnesia for neutral, episodic information in dissociative identity disorder. Journal of Abnormal Psychology 112, 2, 290-297.

Janet P (1901/1977). The mental state of hystericals: A study of mental stigmata and mental accidents. University Publications of America, Washington DC.

Janet P (1907). The major symptoms of hysteria. Macmillan, London/New York.

Janet P (1928). L'évolution de la mémoire et de la notion du temps. A. Chahine, Paris.

Järvilehto T (1998). The theory of the organism-environment system: I. Description of the theory. Integrative Physiological and Behavioral Science 33, 4, 321-334.

Kamen C, Bergstrom J, Koopman C, Lee S, Gore-Felton C (2012). Relationships among childhood trauma, posttraumatic stress disorder, and dissociation in men living with HIV/AIDS. Journal Trauma Dissociation $13,1,102-114$.

Kardiner A (1941). The traumatic neuroses of war. Paul B, Hoeber New York.

Karl A, Schaefer M, Malta LS, Dorfel D, Rohleder N, Werner A (2006). A meta-analysis of structural brain abnormalities in PTSD. Neuroscience and Biobehavioral Reviews 30, 7, 1004-1031.

Koranyi EK (1969). A theoretical review of the survivor syndrome. Diseases of the Nervous Systems 30, 2, Suppl, 115-118.

Kulkarni M, Porter KE, Rauch SA (2012). Anger, dissociation, and PTSD among male veterans entering into PTSD treatment. Journal of Anxiety Disorders 26, 2, 271-278.

Lanius RA, Bluhm RL, Frewen PA (2011). How understanding the neurobiology of complex post-traumatic stress disorder can inform clinical practice: A social cognitive and affective neuroscience approach. Acta Psychiatrica Scandinavica 124, 5, 331-348.

Lanius RA, Bluhm R, Lanius U, Pain C (2006). A review of neuroimaging studies in PTSD: Heterogeneity of response to symptom provocation. Journal of Psychiatry Research 40, 8, 709-729.

Lanius RA, Brand B, Vermetten E, Frewen PA, Spiegel D (2012). The dissociative subtype of posttraumatic stress disorder: Rationale, clinical and neurobiological evidence, and implications. Depression and Anxiety 29, 8, 


\section{Ellert R.S. Nijenhuis}

701-708

Lanius RA, Hopper JW, Menon RS (2003). Individual differences in a husband and wife who developed PTSD after a motor vehicle accident: A functional MRI case study. American Journal of Psychiatry 160, 4, 667-669.

Lanius RA, Vermetten E, Loewenstein RJ, Brand B, Schmahl C, Bremner JD, et al. (2010). Emotion modulation in PTSD: Clinical and neurobiological evidence for a dissociative subtype. American Journal of Psychiatry 167, 6, 640-647.

Lanius RA, Williamson PC, Bluhm RL, Densmore M, Boksman K, Neufeld R.W. et al. (2005). Functional connectivity of dissociative responses in posttraumatic stress disorder: A functional magnetic resonance imaging investigation. Biological Psychiatry 57, 8, 873-884.

Lanius RA, Williamson PC, Boksman K, Densmore M, Gupta M, Neufeld RW et al. (2002). Brain activation during script-driven imagery induced dissociative responses in PTSD: A functional magnetic resonance imaging investigation. Biological Psychiatry 52, 4, 305-311.

Liotti G. (2006). A model of dissociation based on attachment theory and research. Journal of Trauma and Dissociation 7, 4, 55-73.

Müller-Pfeiffer C, Schumacher S, Martin-Soelch C, Pazhenkottil AP, Wirtz G, Fuhrhans C. et al. (2010). The validity and reliability of the German version of the Somatoform Dissociation Questionnaire (SDQ-20). Journal of Trauma and Dissociation 11,3,337-357.

Müller-Pfeiffer C, Rufibach K, Wyss D, Perron N, Pitman R, Rufer M (2013). Screening for dissociative disorders in psychiatric out- and day care-patients. Journal of Psychopathology and Behavioral Assessment 35, 592602.

Myers, C.S. (1940). Shell shock in France 1914-18. Cambridge: Cambridge University Press.

Näring G, Nijenhuis ERS (2005). Relationships between self-reported potentially traumatizing events, psychoform and somatoform dissociation, and absorption, in two non-clinical populations. Australian and New Zealand Journal of Psychiatry 39, 982-988.

Najavits LM, Walsh M (2012). Dissociation, PTSD, and substance abuse: An empirical study. Journal of Trauma and Dissociation 13, 1, 115-126.

Nejad AG, Farahati H (2007). Dissociative disorders and dissociative symptoms among veterans of the Iraq-Iran war suffering from chronic post-traumatic disorder. Neurosciences (Riyadh) 12, 4, 318-321.

Nijenhuis ERS (2004). Somatoform dissociation: phenomena, measurement, and theoretical issues. Norton, New York.

Nijenhuis ERS (2012). Consciousness and self-consciousness in dissociative disorders. In V. Sinason (Ed.) Attachment, trauma and multiplicity: Working on identity and selves, pp. 111-153. Routledge, London.

Nijenhuis ERS, Den Boer JA (2009). Psychobiology of traumatisation and trauma-related structural dissociation of the personality. In PF Dell, JA O'Neil (Eds.) Dissociation and the dissociative disorders: DSM-V and beyond, pp. 337-367. Routledge, New York.

Nijenhuis ER, Spinhoven P, Vanderlinden J, Van Dyck R, Van der Hart O (1998b). Somatoform dissociative symptoms as related to animal defensive reactions to predatory imminence and injury. Journal of Abnormal Psychology 107, 1, 63-73.

Nijenhuis ERS, Spinhoven P, Van Dyck R, Van der Hart O, Vanderlinden J (1996). The development and psychometric characteristics of the Somatoform Dissociation Questionnaire (SDQ-20). Journal of Nervous and Mental Disease 184, 11, 688-694.

Nijenhuis ERS, Van der Hart O (2011). Dissociation in trauma: A new definition and comparison with previous formulations. Journal of Trauma and Dissociation 12, 4, 416-445.

Nijenhuis ERS, Van der Hart O, Kruger K, Steele K (2004). Somatoform dissociation, reported abuse and animal defence-like reactions. Australian and New Zealand Journal of Psychiatry 38, 9, 678-686.

Nijenhuis ERS, Van der Hart O, \& Steele K (2002). The emerging psychobiology of trauma-related dissociation and dissociative disorders. In H. D'Haenen JA Den Boer, \& P Willner (Eds) Biological Psychiatry, pp. 10791098. Wiley, London.

Nijenhuis ERS, Vanderlinden J, Spinhoven P (1998a). Animal defensive reactions as a model for trauma-induced dissociative reactions. Journal of Traumatic Stress 11, 2, 243-260.

NijenhuisERS, Van Dyck R, Spinhoven P, Van derHart O, Chatrou M, Vanderlinden J, MoeneF (1999). Somatoform 
dissociation discriminates between diagnostic categories over and above general psychopathology. Australian and New Zealand Journal of Psychiatry 33, 512-520.

Nijenhuis ERS, Van Engen A, Kusters I, Van der Hart O (2001). Peritraumatic somatoform and psychological dissociation in relation to recall of childhood sexual abuse. Journal of Trauma and Dissociation 2, 3, 49-68.

Northoff G (2003). Philosophy of the brain: The brain problem. John Benjamins, Amsterdam/Philadelphia.

Ogawa JR, Sroufe LA, Weinfield NS, Carlson EA, Egeland B (1997). Development and the fragmented self: Longitudinal study of dissociative symptomatology in a nonclinical sample. Developmental Psychopathology 9, 855-879.

Osuch EA, Benson B, Geraci M, Podell D, Herscovitch P, McCann UD, et al. (2001). Regional cerebral blood flow correlated with flashback intensity in patients with posttraumatic stress disorder. Biological Psychiatry $50,4,246-253$.

Page HW (1891). Railway injuries: With special reference to those of the back and nervous system, in their medico-legal and clinical aspects. Charles Griffin \& Co, London.

Panksepp J (1998). Affective neuroscience: The foundations of human and animal emotions. Oxford University Press, New York.

Panksepp J. Biven L (2012). The archeology of mind: Neuroevolutionary origins of human emotions. W.W. Norton, New York.

Pissiota A, Frans O, Fernandez M, von Knorring L, Fischer H, Fredrikson M (2002). Neurofunctional correlates of posttraumatic stress disorder: A PET symptom provocation study. European Archives of Psychiatry and Clinical Neuroscience 252, 2, 68-75.

Rauch SL, Shin LM, Phelps EA (2006). Neurocircuitry models of posttraumatic stress disorder and extinction: Human neuroimaging research-past, present, and future. Biological Psychiatry 60, 4, 376-382.

Rauch SL, Van der Kolk BA, Fisler RE, Alpert NM, Orr SP, Savage CR, et al. (1996). A symptom provocation study of posttraumatic stress disorder using positron emission tomography and script-driven imagery. Archives of General Psychiatry 53, 5, 380-387.

Rauch SL, Whalen PJ, Shin LM, McInerney SC, Macklin ML, Lasko NB, et al. (2000). Exaggerated amygdala response to masked facial stimuli in posttraumatic stress disorder: A functional MRI study. Biological Psychiatry 47, 9, 769-776.

Reinders AA, Nijenhuis ER, Paans AM, Korf J, Willemsen AT, Den Boer JA (2003). One brain, two selves. Neuroimage 20, 4, 2119-2125.

Reinders AA, Nijenhuis ER, Quak J, Korf J, Haaksma J, Paans AM, et al. (2006). Psychobiological characteristics of dissociative identity disorder: A symptom provocation study. Biological Psychiatry 60, 7, 730-740.

Reinders AA, Willemsen AT, Vos HP, Den Boer JA, Nijenhuis ER (2012). Fact or factitious? A psychobiological study of authentic and simulated dissociative identity states. PLoS One 7, 6, e39279.

Reinders AATS (2014). Neurostructural correlates of trauma and dissociation: A magnetic resonance imaging study in PTSD and DID. Trauma, dissociation, and attachment in the 21st Century: Where are we heading? Fourth Bi-annual International Conference of the European Society for Trauma and Dissociation. Copenhagen, March 27-29.

Rodewald F, Dell PF, Wilhelm-Gossling C, Gast U (2011). Are major dissociative disorders characterized by a qualitatively different kind of dissociation? Journal of Trauma and Dissociation 12, 1, 9-24.

Rodewald F, Wilhelm-Goling C, Emrich HM, Reddemann L, Gast U (2011). Axis-I comorbidity in female patients with dissociative identity disorder and dissociative identity disorder not otherwise specified. Journal of Nervous and Mental Disease 199, 2, 122-131.

Sakamoto H, Fukuda R, Okuaki T, Rogers M, Kasai K, Machida T., et al. (2005). Parahippocampal activation evoked by masked traumatic images in posttraumatic stress disorder: A functional MRI study. Neuroimage 26, 3, 813821.

Schafer I, Langeland W, Hissbach J, Luedecke C, Ohlmeier MD, Chodzinski C, et al. (2009). Childhood trauma and dissociation in patients with alcohol dependence, drug dependence, or both: A multi-center study. Drug Alcohol Dependence 109, 1-3, 84-89.

Schild S, Dalenberg CJ (2012). Psychoform and somatoform dissociation and PTSD in deaf adults. Journal of Trauma and Dissociation 13, 3, 361-376. 


\section{Ellert R.S. Nijenhuis}

Schlumpf YR, Nijenhuis ERS, Chalavi S, Weder EV, Zimmermann E, Luechinger R, La Marca R, Reinders AATS, Jäncke L (2013). Dissociative-part dependent biopsychosocial reactions to backward masked angry and neutral faces: An fMRI study of dissociative identity disorder. Neuroimage Clinical 3, 54-64.

Schopenhauer A (1958). The world as will and representation. Vol. I (1818) and Vol. II (1844). The Falcon's Wing Press, Clinton, MA.

Shin LM, McNally RJ, Kosslyn SM, Thompson WL, Rauch SL, Alpert NM, et al. (1999). Regional cerebral blood flow during script-driven imagery in childhood sexual abuse-related PTSD: A PET investigation. American Journal of Psychiatry 156, 4, 575-584.

Simeon D, Guralnik O, Hazlett EA, Spiegel-Cohen J, Hollander E, \& Buchsbaum MS (2000). Feeling unreal: A PET study of depersonalization disorder. American Journal of Psychiatry 157, 11, 1782-1788.

Trickett PK, Noll JG, \& Putnam FW (2011). The impact of sexual abuse on female development: Lessons from a multigenerational, longitudinal research study. Development and Psychopathology 23, 453-476.

Tomoda A, Sheu YS, Rabi K, Suzuki H, Navalta CP, Polcari A, et al. (2010). Exposure to parental verbal abuse is associated with increased gray matter volume in superior temporal gyrus. Neuroimage 54 Suppl 1, S280-286.

Van Duijl M, Nijenhuis E, Komproe IH, Gernaat HB, De Jong JT (2010). Dissociative symptoms and reported trauma among patients with spirit possession and matched healthy controls in Uganda. Culture, Medicine, and Psychiatry 34, 2, 380-400.

Van der Hart O, Nijenhuis ERS, Steele K. (2005). Dissociation: An insufficiently recognized major feature of complex PTSD. Journal of Traumatic Stress 18, 413-425.

Van der Hart O, Nijenhuis ERS, Steele K (2006). The haunted self: Structural dissociation and the treatment of chronic traumatization. Norton, New York.

Van der Hart O, Van Ochten JM, Van Son MJ, Steele K, Lensvelt-Mulders G (2008). Relations among peritraumatic dissociation and posttraumatic stress: a critical review. Journal of Trauma and Dissociation 9, 4, 481-505.

Varela F (1996). Neurophenomenology: A methodological remedy for the hard problem. Journal of Consciousness Studies 3, 4, 330-349.

Vermetten E, Schmahl C, Lindner S, Loewenstein RJ, Bremner JD (2006). Hippocampal and amygdala volumes in dissociative identity disorder. American Journal of Psychiatry 163, 4, 630-636.

Wang S, Wilson JP, Mason JW (1996). Stages of decompensation in combat-related posttraumatic stress disorder: A new conceptual model. Integrative Physiolology \& Behavioral Science 31, 237-253.

Wechsler-Zimring A, Kearney CA (2011). Posttraumatic stress and related symptoms among neglected and physically and sexually maltreated adolescents. Journal of Traumatic Stress 24, 5, 601-604.

Wilson JP, Drozdek B, Turkovic S (2006). Posttraumatic shame and guilt. Trauma Violence Abuse 7, 2, 122-141.

Wolf EJ, Miller MW, Reardon AF, Ryabchenko KA, Castillo D, Freund R (2012). A latent class analysis of dissociation and posttraumatic stress disorder: Evidence for a dissociative subtype. Arch Gen Psychiatry 69, 7, 698-705.

Woon FL, Sood S, Hedges DW (2010). Hippocampal volume deficits associated with exposure to psychological trauma and posttraumatic stress disorder in adults: A meta-analysis. Progress in Neuropsychopharmacology and Biological Psychiatry 34, 7, 1181-1188.

World Health Organisation (1992). ICD-10. The ICD-10 classification of mental and behavioural disorders: Clinical descriptions and diagnostic guidelines. Switzerland, Author, Geneva.

Zucker M, Spinazzola J, Blaustein M, Van der Kolk BA (2006). Dissociative symptomatology in posttraumatic stress disorder and disorders of extreme stress. Journal of Trauma and Dissociation 7, 1, 19-31.

\section{Correspondence}

Ellert R.S. Nijenhuis

Top Referent Trauma Center Mental Health Care DrentheAssen, The Netherlands

Boermaat 14, 9431MS Westerbork, The Netherlands

Email: enijenhuis@me.com

Tel. 0031643246347 